\title{
First report of Hemileia wrightiae on Wrightia spp. in Australia
}

\author{
J. R. Liberato • R. G. Shivas
}

Received: 10 March 2011 / Accepted: 19 September 2011/Published online: 1 October 2011

(C) Australasian Plant Pathology Society Inc. 2011

\begin{abstract}
The rust fungus Hemileia wrightiae is reported for the first time in Australia on Wrightia saligna and $W$. pubescens. This is the first species of Hemileia that has been found in Australia. The rust is described and illustrated from Australian specimens.
\end{abstract}

Keywords Uredinales Pucciniales

Wrightia (Apocynaceae) is a genus of about 23 species distributed across tropical Africa and Asia (Mabberley 2008), including four species that occur in Australia (Clifford and Ludlow 1972). Two of these, Wrightia pubescens $\mathrm{R}$. Br. and $W$. saligna (R. Br.) F. Muell. ex Benth., are small trees distributed across tropical regions in the Northern Territory, Queensland and Western Australia.

The uredinial and telial stages of leaf rust were examined from fresh specimens on seedlings of $W$. pubescens and W. saligna collected from a plant nursery near Darwin, NT in late 2010 as well as from fresh specimens collected from near Charters Towers, Qld in

J. R. Liberato $(\square)$

Department of Resources, Plant Pathology Section,

GPO Box 3000,

Darwin, NT 0801, Australia

e-mail: jose.liberato@nt.gov.au

R. G. Shivas

Plant Pathology Herbarium, Agri-Science Queensland,

41 Boggo Road,

Dutton Park, Qld 4102, Australia early 2011. A further unidentified rust on $W$. saligna that had been collected in the NT in 2001 and deposited as a herbarium specimen was also examined. The rust was examined by mounting spores in lactic acid on microscope slides and gently heating to expel air bubbles. The slides were examined with Leica DM series compound microscopes using differential interference contrast and images taken with Leica DFC500 cameras. Measurements were obtained only from turgid urediniospores and teliospores.

The rust was identified as Hemileia wrightiae (Racib.) P. Syd. \& Syd., according to the descriptions provided by Sydow and Sydow (1914), Stevens (1932) and Ritschel (2005). The description of the rust based on these Australian specimens follows.

Hemileia wrightiae (Racib.) P. Syd. \& Syd. (Figs. 1, 2, 3 and 4)

Monographia Uredinearum 3: 218 (1915).

$\equiv$ Hemileiopsis wrightiae Racib., Parasitische Algen und Pilze Javas 1: 26 (1900). Lectotype on Wrightia tomentosa (as W. mollisima Wall.), Indonesia, Java, Bogor (as Buitenzorg), 1899, M. Raciborski (Raciborski, Crypt. Paras. Java No. 34 (M)); isolectotypes: B, M (as Sydow, Uredineen No. 2290), NY; fide Ritschel (2005: 68).

Specimens examined: AUSTRALIA, NORTHERN TERRITORY: Berrimah, Thorak Road, on seedling of $W$. pubescens, 23 Sept. 2010, M. Connelly (DNAP 4606), II; on seedlings of $W$. saligna, 18 Nov. 2010, M. Connelly (DNAP 4491), II; Kakadu National Park, Border Store, about $170 \mathrm{~m}$ from the west margin of the East Alligator 

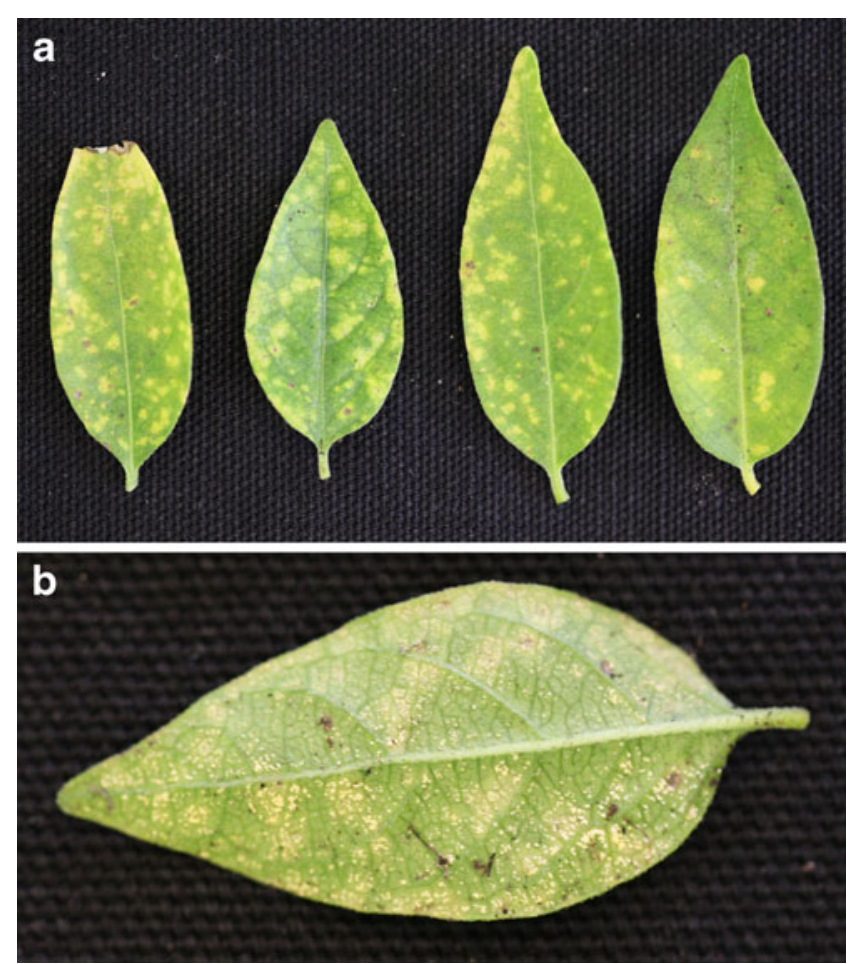

Fig. 1 Hemileia wrightiae on Wrightia pubescens (DNAP 4606). a Symptoms on the upper leaf surface. b Signs on the lower leaf surface
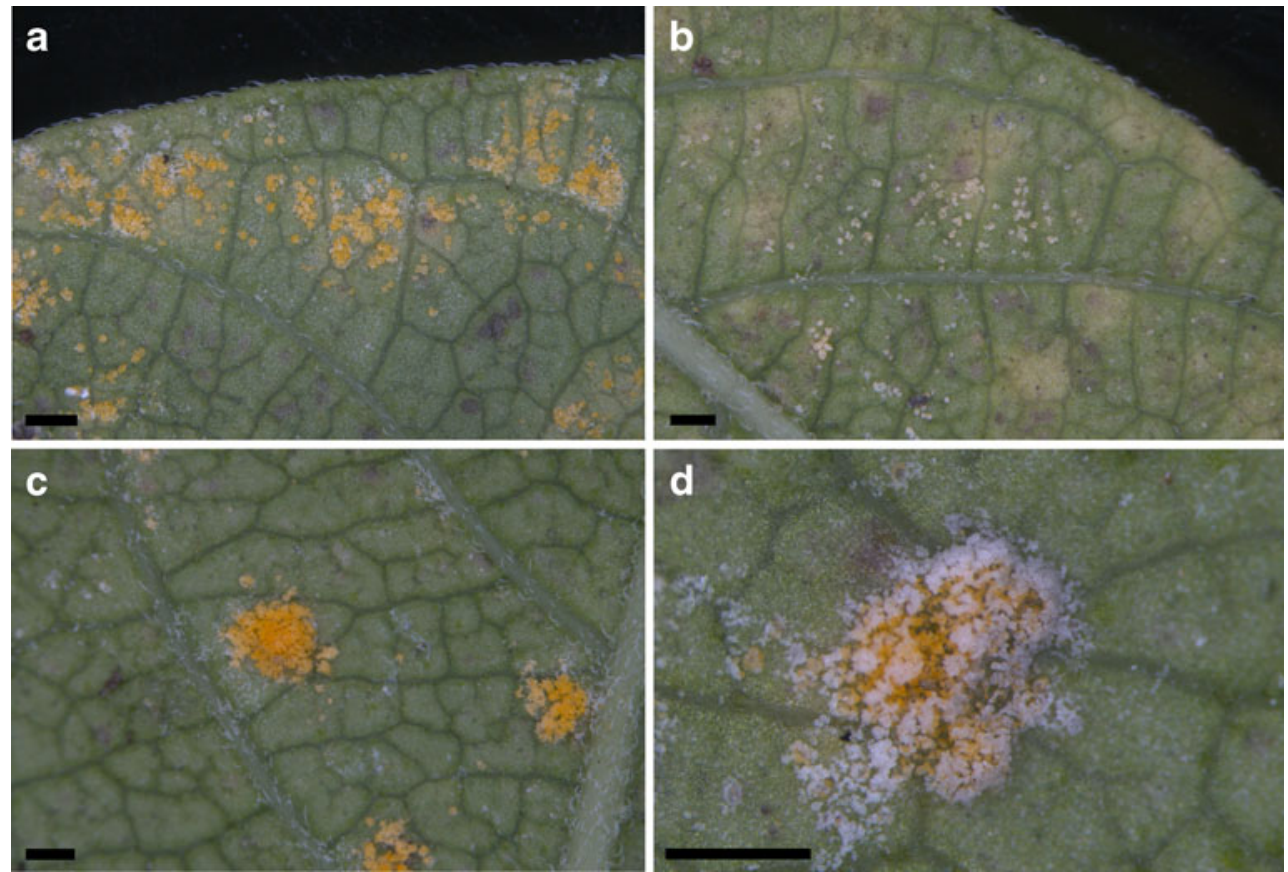

Fig. 2 a-d Uredinia of Hemileia wrightiae on a fresh lower leaf surface of Wrightia pubescens seen under stereo microscope (DNAP 4606). b Discoloured uredinia, $\mathbf{d}$ Discoloured urediniospores surrounding orange urediniospores on uredinia. $($ Bar $=1 \mathrm{~mm})$ 
Fig. 3 a-g Hemileia wrightiae. a Teliospores (smooth, "Napoleon Hat" shaped) and urediniospores (echinulated). b-g Urediniospores. a-b BRIP 51425. c-g DNAP 4606. $($ Bars $=20 \mu \mathrm{m})$
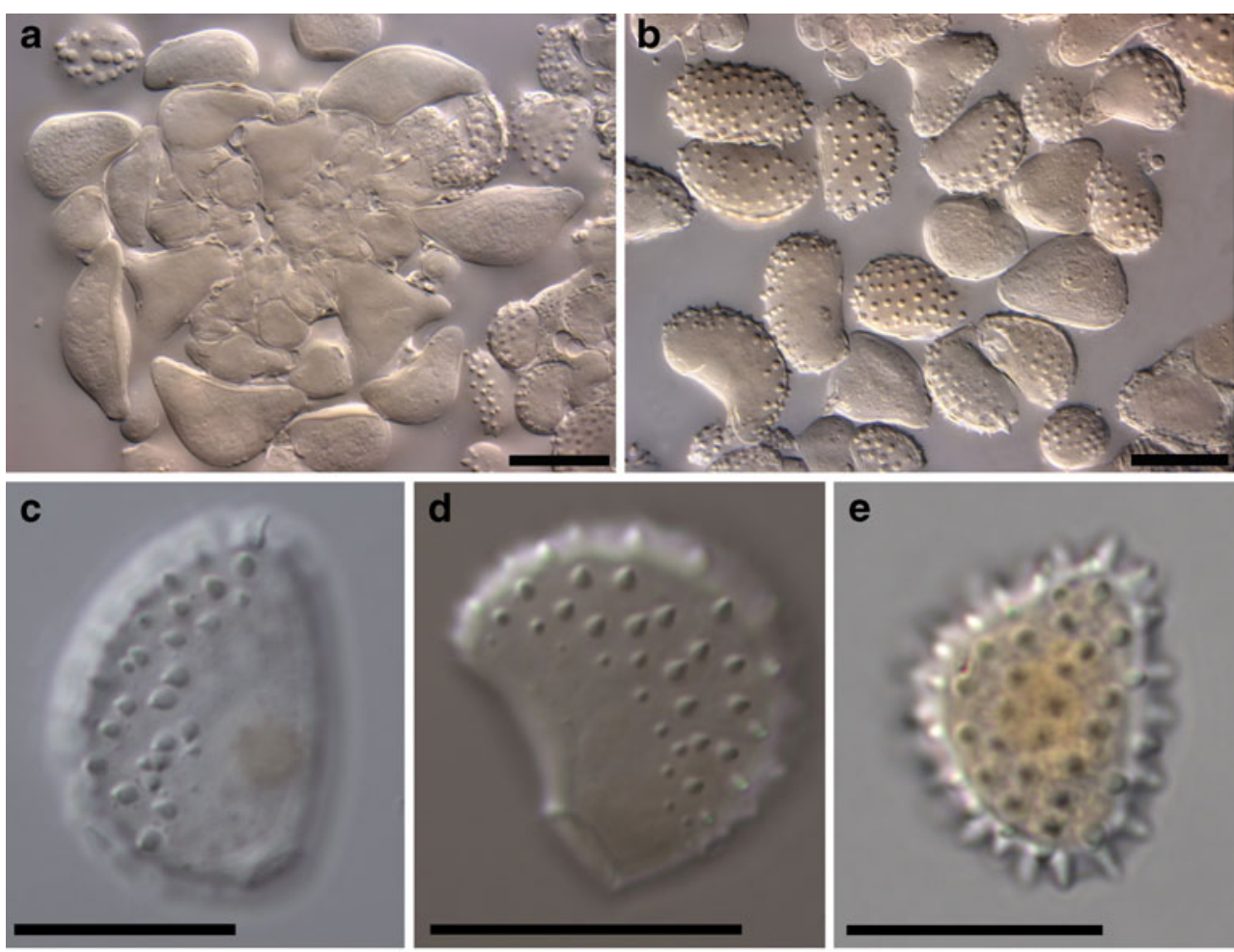

e
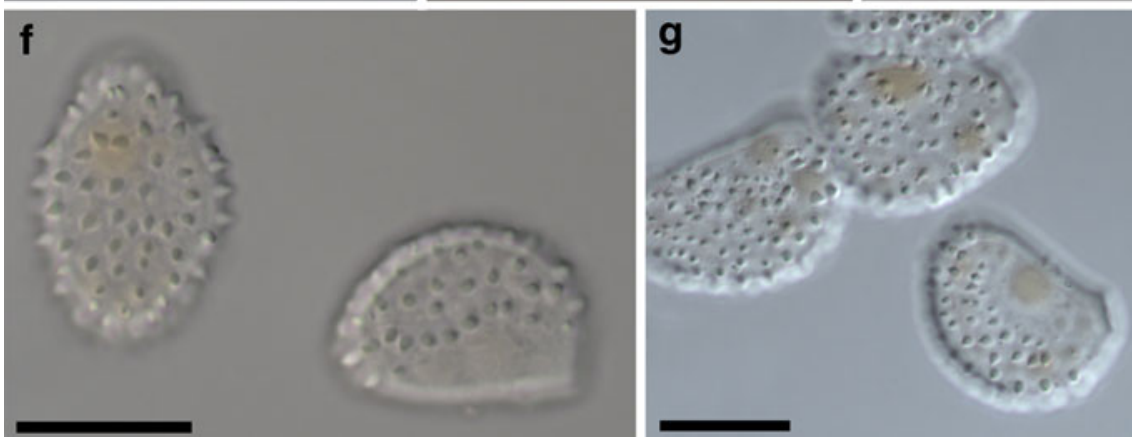

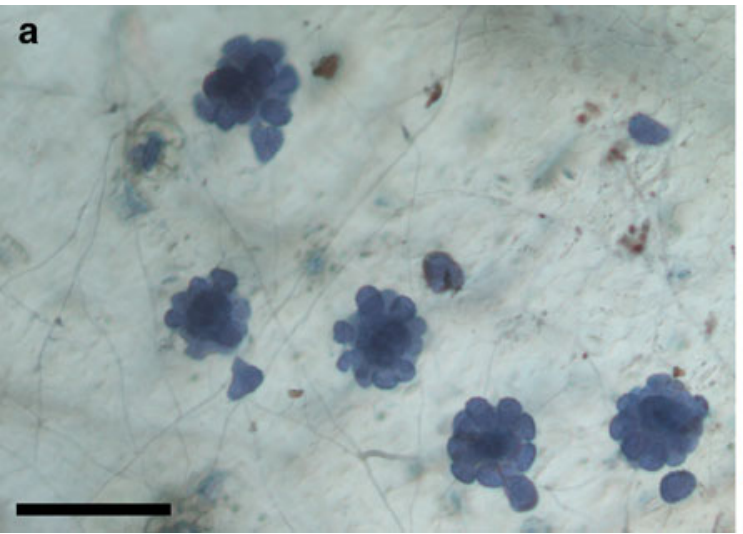

b

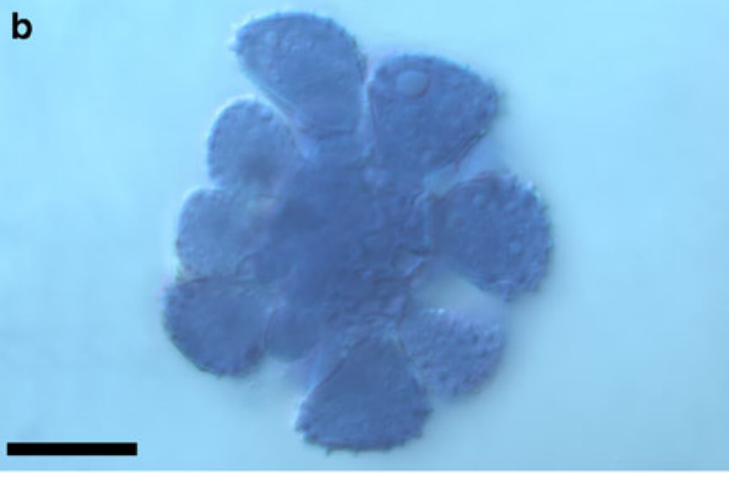

Fig. 4 Stained Hemileia wrightiae (DNAP 4606) on Wrightia pubescens. a Uredinia on leaf (bar $=100 \mu \mathrm{m})$. b Upper view of an uredinium $($ bar $=20 \mu \mathrm{m})$ 
River and $340 \mathrm{~m}$ from the north margin of the Oenpelli Road, on W. saligna, 31 Jan. 2001, M.P. Weinert (BRIP 51425), II, III. QUEENSLAND: near Charters Towers, between Haughton River and Reid River, on $W$. pubescens, 23 Fe. 2011, C.A. Pearce \& M. Berridge (BRIP 54123), II, III.

Spermogonia and aecia absent. Uredinia hypophyllous (amphigenous on W. saligna, which has stomata present on both leaf surfaces and in approximately equal numbers (Ngan 1965)), corresponding to chlorotic spots on the upper leaf surface, numerous, pulverulent sometimes covering the entire lower leaf surface, orange, suprastomatal, 50-110 $\mu \mathrm{m}$ in diam.; urediniospores borne singly on short pedicels, orange, strongly asymmetrical, kidney-shaped or ellipsoidal to triangular (depending on angle viewed), 17-32 $\times 14$ $25 \mu \mathrm{m}$, wall $1.0-1.5 \mu \mathrm{m}$ wide, usually with a concave smooth side and a dorsally convex coarsely echinulate side, with conical spines up to $2 \mu \mathrm{m}$ high and $2 \mu \mathrm{m}$ wide at base, germpores obscure. Teliospores form in the same sori as the urediniospores, "Napoleon Hat" shaped or irregular with lobes and a dorsally convex side, 21-38×10-22 $\mu \mathrm{m}$, subhyaline, wall $1 \mu \mathrm{m}$ thick, smooth, germinating without dormancy to form cylindrical 4-celled basidia that are up to $80 \times 10 \mu \mathrm{m}$ bearing 4 basidiospores c. $8 \mu \mathrm{m}$ diam.

Spermogonia and aecia are unknown for the genus Hemileia (Cummins and Hiratsuka 2003, Ritschel 2005). Stevens (1932) described aecia for $H$. wrightiae on $W$. pubescens ( $=$ W. laniti (Blanco) Merr.). Thirumalachar's (1947) inoculation experiments gave negative results when basidiospores produced by teliospores of $H$. wrightiae were inoculated on young leaves of $W$. tinctoria $\mathrm{R}$. Br. Teliospores germinated within $5 \mathrm{~h}$ but no signs of infection appeared within 20 days. Thirumalachar (1947) considered that $H$. wrightiae must be heteroecious and further suggested that Stevens (1932) may have mistaken uredinia for aecia.
Hemileia wrightiae has been previously found in Indonesia, Philippines, Taiwan, India and Sri Lanka, on the following species: Wrightia arborea (Dennst.) Mabb. (=W. tomentosa (Roxb.) Roem \& Schult.), W. javanica DC., W. mollissima, $W$. pubescens, $W$. tinctoria, $W$. antidysenterica (L.) R.Br. (= W. zeylanica (L.) R. Br.) and Wrightia sp. (Sydow and Sydow 1914, Ramakrishnan and Soumini 1946, Thirumalachar 1947, Bagyanarayana et al. 2003, Ritschel 2005). This discovery represents the first report of the genus Hemileia in Australia and the first report of H. wrightiae on W. saligna.

\section{References}

Bagyanarayana G, Ramesh P, Srinivasulu U, Raju M, Chapla J (2003) New records of rust species (Uredinales) from Andhra Pradesh. J Mycol Plant Pathol 33(1):76-79

Clifford HT, Ludlow G (1972) Keys to the families and genera of Queensland flowering plants. University of Queensland Press, St Lucia

Cummins GB, Hiratsuka Y (2003) Illustrated genera of rust fungi, 3rd edn. APS, St. Paul, 225p

Mabberley DJ (2008) Mabberley’s plant book, 3rd edn. Cambridge University Press, UK

Ngan PT (1965) A revision of the genus Wrightia (Apocynaceae). Ann Mo Bot Gard 52:114-175

Ramakrishnan TS, Soumini CK (1946) Hemileia wrightiae Rac. on Wrightia tinctoria R. Br., and W. tomentosa Roem. and Sch. Curr Sci 15:256-257

Ritschel A (2005) Monograph of the genus Hemileia (Uredinales). Bibl Mycol 200:1-132

Stevens FL (1932) Two rusts on Wrightia Laniti (Blco.) Merr. Philipp Agric 20:627-631

Sydow P, Sydow H (1914) Hemileia wrightiae. Monographia Uredinearum 3:218-219

Thirumalachar MJ (1947) Some noteworthy rusts-II. Mycologia 39 (2):231-248 